\title{
Cholinergic Septal Afferent Terminals Preferentially Contact Neuropeptide Y-Containing Interneurons Compared to Parvalbumin-Containing Interneurons in the Rat Dentate Gyrus
}

\author{
Karen D. Dougherty ${ }^{2}$ and Teresa A. Milner ${ }^{1}$ \\ ${ }^{1}$ Department of Neurology and Neuroscience, Weill Medical College of Cornell University, New York, New York 10021, \\ and ${ }^{2}$ Department of Neuroscience and Cell Biology, University of Medicine and Dentistry, Robert Wood Johnson Medical \\ School, Piscataway, New Jersey 08854
}

\begin{abstract}
Septal cholinergic neurons may affect hippocampal memory encoding and retrieval by differentially targeting parvalbumin (PARV)-containing basket cells and neuropeptide Y (NPY) interneurons. Thus, the cellular associations of cholinergic efferents, identified by the low-affinity, p75 neurotrophin receptor (p75 NTR), with interneurons containing either PARV or NPY in the hilus of the rat dentate gyrus were examined in single sections using dual labeling immunoelectron microscopy. Most profiles immunoreactive (IR) for PARV and NPY were perikaryal and dendritic and found within the infragranular and central hilar regions, respectively, whereas most profiles with p75 NTR labeling were unmyelinated axons and axon terminals. Although PARV-labeled profiles were more numerous, p75 NTR labeled axons and terminals contacted few PARV-IR profiles compared to NPY-labeled profiles ( $2 \%$ of 561 for PARV vs $12 \%$ of 433 for NPY). Moreover, structures targeted by $\mathrm{p} 75^{\mathrm{NTR}}$-IR axon terminals varied depending on the presence of PARV or NPY immunoreactivity. p75 ${ }^{\text {NTR }}$-IR terminals primarily con-
\end{abstract}

Neurons in the medial septum-diagonal band complex provide a major subcortical input to the hippocampal formation (HF) (Swanson and Cowan, 1979; Senut et al., 1989). Septohippocampal neurons include cholinergic and noncholinergic populations, the latter mostly containing GABA (Köhler et al., 1984; Amaral and Kurz, 1985; Freund and Antal, 1988). Cholinergic septohippocampal neurons are believed to influence memory and attentional processing (Chiba et al., 1995; Baxter et al., 1997); moreover, loss of these neurons is associated with age- and Alzheimer's-related memory declines (Muir, 1997).

Septal afferents are topographically arranged within the HF with many terminating in the hilus of the dentate gyrus (Swanson and Cowan, 1979; Milner et al., 1983). Although they contact principal and nonprincipal (GABAergic interneurons) hippocampal cells (Frotscher, 1991; Dougherty and Milner, 1999), GABAergic and cholinergic septal axons have different patterns of connectivity. GABAergic septohippocampal terminals prefer-

Received June 17, 1999; revised Aug. 19, 1999; accepted Sept. 3, 1999.

This work was supported by National Institutes of Health Grants MH42834, DA08259, and HL18974 (T.A.M.) and National Institutes of Health training Grant NS07384 (K.D.D.). We thank Ms. Sabrina Prince and Mr. Peter Chang for technical assistance. We also thank Drs. Carrie T. Drake and Joseph P. Pierce for their helpful comments on this manuscript.

Correspondence should be addressed to Dr. Teresa A. Milner, Division of Neurobiology, Weill Medical College of Cornell University, 411 East $69^{\text {th }}$ Street, New York, NY 10021. E-mail: tmilner@mail.med.cornell.edu.

Copyright (C) 1999 Society for Neuroscience 0270-6474/99/1910140-13\$05.00/0 tacted PARV-IR dendrites (87\%) compared to somata (13\%); however, they contacted more NPY-IR somata (57\%) than dendrites (43\%). p75 ${ }^{\mathrm{NTR}}$-labeled terminals formed exclusively symmetric (inhibitory-type) synapses with PARV-IR somata and dendrites; however, they formed mostly symmetric but also asymmetric (excitatory-type) synapses with NPY-IR somata and dendrites. These results suggest that septal cholinergic efferents in the dentate gyrus: (1) preferentially innervate NPYcontaining interneurons compared to PARV-containing basket cells; and (2) may provide a more powerful (i.e., somatic contacts), yet functionally diverse (i.e., asymmetric and symmetric synapses), modulation of NPY-containing interneurons. Moreover, they provide evidence that neurochemical subsets of hippocampal interneurons can be distinguished by afferent input.

Key words: neurotrophin receptors; septohippocampal pathway; nerve growth factor; electron microscopy; GABAergic nonprincipal cells; neuropeptide $Y$ entially contact GABAergic basket interneurons and almost exclusively form symmetric synapses (Freund and Antal, 1988). Many of these basket interneurons contain the calcium-binding protein parvalbumin (PARV) and are primarily in the infragranular hilus (Kosaka et al., 1987; Freund, 1989; Deller et al., 1994; Freund and Buzsáki, 1996). In contrast, cholinergic septohippocampal terminals are thought to form both asymmetric and symmetric synapses indiscriminately with granule cells and hilar GABAergic interneurons (Clarke, 1985; Frotscher, 1991).

However, we recently reexamined the ultrastructural distribution of cholinergic septal terminals in the dentate gyrus using p75 neurotrophin receptor $\left(\mathrm{p} 75^{\mathrm{NTR}}\right)$ immunoreactivity, which is not detected in GABAergic septal neurons (Koliatsos et al., 1994). This study revealed that $\mathrm{p} 75^{\mathrm{NTR}}$-immunoreactive (IR) axons and axon terminals were more numerous in the central hilus, suggesting that they preferentially contacted interneurons rather than granule cells (Dougherty and Milner, 1999). Previous studies support this notion and further suggest that GABAergic interneurons targeted by septal cholinergic terminals may contain neuropeptide Y (NPY). First, septal afferents, morphologically similar to cholinergic terminals, form numerous contacts on hilar NPY-containing interneurons (Milner and Veznedaroglu, 1993). Second, cholinergic septal deafferentation using 192 IgG-saporin leads to rapid and selective decreases in the number of NPYcontaining hilar interneurons (Milner et al., 1997). This NPY- 
labeled interneuron loss is restricted to a subset located primarily in the central hilus and distinct from infragranular GABAergic basket cells (Milner et al., 1997, 1999). However, whether septal cholinergic neurons preferentially contact subpopulations of GABAergic interneurons in the dentate gyrus remains to be demonstrated.

Understanding the targeting specificity of septal cholinergic afferents with subpopulations of GABAergic interneurons could have important implications for hippocampal function. In particular, growing evidence indicates that functionally and morphologically distinct interneuron subtypes might modulate selective types of hippocampal-dependent memory processes (Han et al., 1993; Halasy and Somogyi, 1993; Klapstein and Colmers, 1997; Sik et al., 1997; Paulsen and Moser, 1998). Thus, the present study sought to determine whether septal cholinergic afferent terminals differentially innervate subpopulations of GABAergic interneurons containing NPY or PARV in the dentate gyrus. For this, the proportion of cholinergic axon terminals (identified with p $75^{\text {NTR }}$ immunoreactivity) that contacted hilar NPY- or PARV-IR perikarya and dendrites was compared using electron microscopy.

\section{MATERIALS AND METHODS}

Section preparation. Nine naive male Sprague Dawley rats (250-300 gm; Taconic, Germantown, NY) were used in these studies. All methods were approved by the Weill Medical College of Cornell University Institutional Animal Care and Use Committee and conform to National Institutes of Health guidelines. Rats were anesthetized with Nembutal (150 mg/kg, i.p.), and their brains were fixed by ascending aortic arch perfusion sequentially with solutions of: (1) $10-15 \mathrm{ml}$ of normal saline $(0.9 \%$ ) containing $1000 \mathrm{U} / \mathrm{ml}$ of heparin, (2) $50 \mathrm{ml}$ of $3.75 \%$ acrolein (Polysciences, Warrington, PA) and 2\% paraformaldehyde in $0.1 \mathrm{M}$ phosphate buffer (PB; pH 7.4), and (3) $200 \mathrm{ml}$ of $2 \%$ paraformaldehyde in $\mathrm{PB}$. For the immunogold-silver procedure, all rats were injected with the zinc chelator DEDTC $(1 \mathrm{mg} / \mathrm{kg}$, i.p.) $15 \mathrm{~min}$ before perfusion to reduce nonspecific silver labeling of mossy fibers (Milner and Veznedaroglu, 1993). The region of the forebrain containing the HF was removed, cut into a 5-mm-thick coronal block and placed in the latter fixative $(30 \mathrm{~min})$. The brains then were sectioned $(40-\mu \mathrm{m}$-thick) on a vibrating microtome (Vibratome) and collected in PB. Before immunocytochemical processing, sections were placed into $1 \%$ sodium borohydride in PB (30 min).

Antibodies. For immunohistochemical localization of the $\mathrm{p} 75^{\mathrm{NTR}}$, two antibodies were used. In a previous investigation, we found that both of these antibodies labeled the same cellular profiles with the same subcellular distribution (Dougherty and Milner, 1999). Specificity of both antibodies has been tested previously (Chandler et al., 1984; Dobrowsky et al., 1994). The polyclonal antibody raised in rabbit (Promega, Madison, WI), which recognizes the cytoplasmic domain of the p $75^{\mathrm{NTR}}$, was used in double-labeling experiments with antibodies for PARV. The monoclonal antibody derived from mouse $192 \mathrm{IgG}$, which recognizes the extracellular domain of the $75^{\mathrm{NTR}}$ (Boehringer Mannheim, Indianapolis, IN) was used in double-labeling experiments with antiserum for NPY. A polyclonal antiserum raised in rabbits against NPY (Peninsula, Belmont, CA) and a monoclonal antibody raised in mice to PARV (Sigma, St. Louis, MO) (both diluted 1:2000) have been previously tested for specificity to their respective peptides, using both preadsorption and immunodot blot techniques (Sloviter and Nilavier, 1987; Milner and Veznedaroglu, 1992).

Dual immunocytochemical labeling. To reduce variability attributable to differences in fixation and solutions between the dual-labeling conditions, tissue collected from each rat was labeled using both conditions on the same day. For dual immunocytochemical localization of $\mathrm{p} 75^{\mathrm{NTR}}$ and PARV or NPY, prepared sections through the HF were processed by using a combined immunoperoxidase and immunogold-silver labeling technique (Chan et al., 1990). Sections were incubated for $48 \mathrm{hr}$ at $4^{\circ} \mathrm{C}$ in a $0.1 \%$ bovine serum albumin (BSA) and a Tris-buffered saline (TBS, $\mathrm{pH}=7.6$ ) solution containing either: (1) rabbit polyclonal antiserum for p $75^{\text {NTR }}$ at 1:2000 dilution and mouse monoclonal antibody for PARV at 1:1000 dilution, or (2) mouse monoclonal antibody for $\mathrm{p} 75^{\mathrm{NTR}}$ at 1:300 dilution and rabbit polyclonal antiserum for NPY at 1:2000 dilution.
After incubation with these primary antisera, sections were dually labeled for either of the two antibody combinations using immunoperoxidase followed by immunogold-silver detection.

For immunoperoxidase labeling, sections were incubated in either biotinylated donkey anti-rabbit (for detection of $\mathrm{p} 75^{\mathrm{NTR}}$ immunoreactivity in combination with PARV labeling) or rat anti-mouse $\operatorname{IgG}$ (for detection of p $75^{\text {NTR }}$ immunoreactivity in combination with NPY labeling) (Vector Laboratories, Burlingame, CA; 1:400 in 0.1\% BSA-TBS) for $30 \mathrm{~min}$. After rinses with TBS, sections were incubated in avidinbiotin-peroxidase complex (Vectastain Elite kit; Vector Laboratories; 1:100 in TBS) for $30 \mathrm{~min}$. Bound peroxidase was visualized by $6 \mathrm{~min}$ incubation in $0.022 \%$ 3,3'-diaminobenzidine (DAB; Aldrich, Milwaukee, WI) and $0.003 \%$ hydrogen peroxide in TBS.

For immunogold-silver labeling, sections were rinsed in $0.01 \mathrm{M}$ PBS, $\mathrm{pH} 7.4$, blocked in $0.8 \%$ BSA and $0.1 \%$ gelatin in PBS for $10 \mathrm{~min}$, then incubated in either goat anti-mouse (for detection of PARV immunoreactivity) or goat anti-rabbit (for detection of NPY immunoreactivity) IgG conjugated to $1 \mathrm{~nm}$ gold particles (AuroProbe; Amersham, Arlington Heights, IL; 1:50 in BSA-gelatin blocking solution) for $2 \mathrm{hr}$. Sections were rinsed in PBS and post-fixed in 2\% glutaraldehyde in PBS for 10 min. To obtain optimal visualization of immunogold labeling, gold particles bound to the sections were silver-enhanced for 6-7 min (IntenSE kit; Amersham).

For electron microscopy, labeled sections were fixed for $1 \mathrm{hr}$ in $2 \%$ osmium tetroxide in $0.1 \mathrm{M} \mathrm{PB}$ and embedded in EMBed (Electron Microscopy Sciences, Fort Washington, PA) between two sheets of Aclar plastic as described previously (Milner and Veznedaroglu, 1992). Sections through the dentate gyrus were mounted onto EMBed blocks, and ultrathin sections (70-nm-thick) from the tissue-plastic interface of each section were cut with a diamond knife, collected on 400 mesh copper grids, and counterstained with uranyl acetate and Reynolds lead citrate. Final preparations were examined with a Philips 201 electron microscope. Final illustrations were generated from scanned photographic prints with a Power Macintosh 8500/120 (Apple Computer, Cupertino, CA) using Adobe Photoshop 4.0 (Adobe Systems, Mountain View, CA) and Quark X-Press 3.32 (Quark, Denver, CO).

Electron microscopic analysis. Electron microscopic analysis of dual immunocytochemical labeling was conducted on those six rats in which ultrathin sections collected from the dentate gyrus displayed optimal morphological preservation and robust immunolabeling of the $\mathrm{p} 75^{\mathrm{NTR}}$ and either PARV or NPY. The hippocampal nomenclature used in this study is that reviewed in Patton and McNaughton (1995). The term "infragranular hilus" denotes that region of the hilus $\sim 55 \mu \mathrm{m}$ below the granule cell layer.

Ultrastructural nomenclature was in agreement with Peters et al. (1991). Neuronal perikarya were identified by the presence of a nucleus. Dendrites contained endoplasmic reticulum, were usually postsynaptic to axon terminals, and ranged from $0.5-4.5 \mu \mathrm{m}$ in diameter. Axons were defined as those profiles containing filaments but few synaptic vesicles and having a cross-sectional diameter of $0.1-0.2 \mu \mathrm{m}$. Axon terminals were defined as those profiles with a cross-sectional diameter of $\geq 0.3 \mu \mathrm{m}$ in which small synaptic vesicles could clearly be seen. Those immunoreactive profiles that could not be identified because of distorted or compromised morphology were categorized as "undefined." Asymmetric synapses contained thick postsynaptic densities, whereas symmetric synapses had thin postsynaptic densities. Appositions were defined as those contacts between profiles in which no interposing glial processes were found but which lacked any recognizable synaptic specializations. A profile was defined as immunogold-silver-labeled when two or more particles were seen in large profiles or a single particle in small profiles, such as small unmyelinated axons and dendritic spines that could be traced in serial sections. Immunoperoxidase-labeled profiles were identified as those containing dense precipitate.

A total of 10 coronal vibratome sections were examined in this study. The final quantitative analysis is based on data obtained from two blocks of tissue from each of three rats. For each lamina of the dentate gyrus, three grid squares were analyzed (with total area of $9075 \mu \mathrm{m}^{2}$ ). Four laminae were examined [central hilus $(\mathrm{CNH})$, infragranular hilus (IGH), granule cell layer (GCL), and inner molecular layer (IML)] for a total of $36,300 \mu \mathrm{m}^{2}$ of tissue analyzed per block of tissue, for each dual labeling condition. Only fields adjacent to the plastic-tissue interface were selected. For this, all immunogold-silver labeled profiles were counted, categorized (e.g., perikarya, dendrites, axons and terminals, glia) and 
described in terms of their laminar location. For each block of tissue examined, the total number of immunogold-silver-labeled profiles was determined, from which the percentage of those in each profile category and each lamina contacted by $\mathrm{p} 75^{\mathrm{NTR}}$-labeled axons and axon terminals was calculated. The data are expressed as either mean percent \pm SEM or percentage of total observed. The types of contact relationships were identified and classified as defined above. $\chi^{2}$ analysis and factorial ANOVAs were used to compare the data obtained from PARV- and NPY-immunolabeled tissue sections.

\section{RESULTS}

\section{Light microscopic examination of p75 ${ }^{\mathrm{NTR}}$-, PARV-, and NPY-IR}

In agreement with previous reports (Pioro and Cuello, 1990; Dougherty and Milner, 1999), p75 ${ }^{\text {NTR }}$-IR was found in fine varicose processes and puncta throughout the dentate gyrus. Dense $\mathrm{p} 75^{\mathrm{NTR}}$-IR was clustered in the supragranular and infragranular regions, whereas diffuse $\mathrm{p} 75^{\mathrm{NTR}}$-IR was observed throughout the remaining dentate laminae (Fig. $1 A$ ). Distribution patterns of immunocytochemical labeling of PARV and NPY in neuronal cell bodies and fibers also were similar to those previously reported (Fukuda et al., 1996; Milner et al., 1997). Most PARV-IR neuronal perikarya and dendrites were located in the infragranular region of the hilus (Fig. 1B). Occasionally, PARV-IR perikarya and dendrites were seen in the central hilus and molecular layer (Fig. 1B). NPY-IR neurons and dendritic processes were seen primarily in the hilus (Fig. 1C). Although a few NPY-labeled perikarya were observed in the infragranular region of the hilus, the majority were in the central portion.

\section{Electron microscopy}

$p 75^{N T R}$ immunoreactivity is primarily presynaptic

In agreement with our previous reports (Dougherty and Milner, $1998,1999)$, the majority of p $75^{\text {NTR }}$ immunoreactivity was found in axons and axon terminals (Figs. 2-4). Less frequently, glial processes, dendritic shafts, and dendritic spines contained p $75^{\text {NTR }}$ immunolabeling (data not shown). In the present investigation, the distribution and morphological characteristics of the p75 ${ }^{\text {NTR }}$-IR axonal profiles within the dentate gyrus were identical when either the monoclonal antibody 192 IgG or the polyclonal antiserum raised in rabbit for the $\mathrm{p} 75^{\mathrm{NTR}}$ was used. $\mathrm{p} 75^{\mathrm{NTR}}$-IR profiles were most numerous within the inner molecular layer, infragranular hilus, and central hilus. p75 NTR immunoreactivity was found predominantly within small $(0.1-0.3 \mu \mathrm{m}$ in diameter) unmyelinated axons and small to medium (0.3-0.8 $\mu \mathrm{m}$ diameter) axon terminal profiles (Fig. 2). p75 ${ }^{\text {NTR }}$-IR axon terminals contained many small synaptic vesicles and mitochondria, but no dense core vesicles.

\section{PARV immunoreactivity is in basket cells}

PARV immunogold-silver-labeled neuronal profiles observed in the present investigation closely resembled those described in previous reports in which immunoperoxidase labeling was used (Ribak et al., 1990; Deller et al., 1994). Briefly, PARV-IR neuronal profiles had the morphological characteristics of basket cells: (1) small (6-12 $\mu \mathrm{m}$ in diameter) and aspinous perikarya, (2) nuclei with Nissl bodies, intranuclear rods, and nuclear infoldings (data not shown), (3) aspinous dendrites that received numerous contacts from terminals forming both asymmetric and symmetric synapses (Figs. 2B,3), and (4) axon terminals that form symmetric
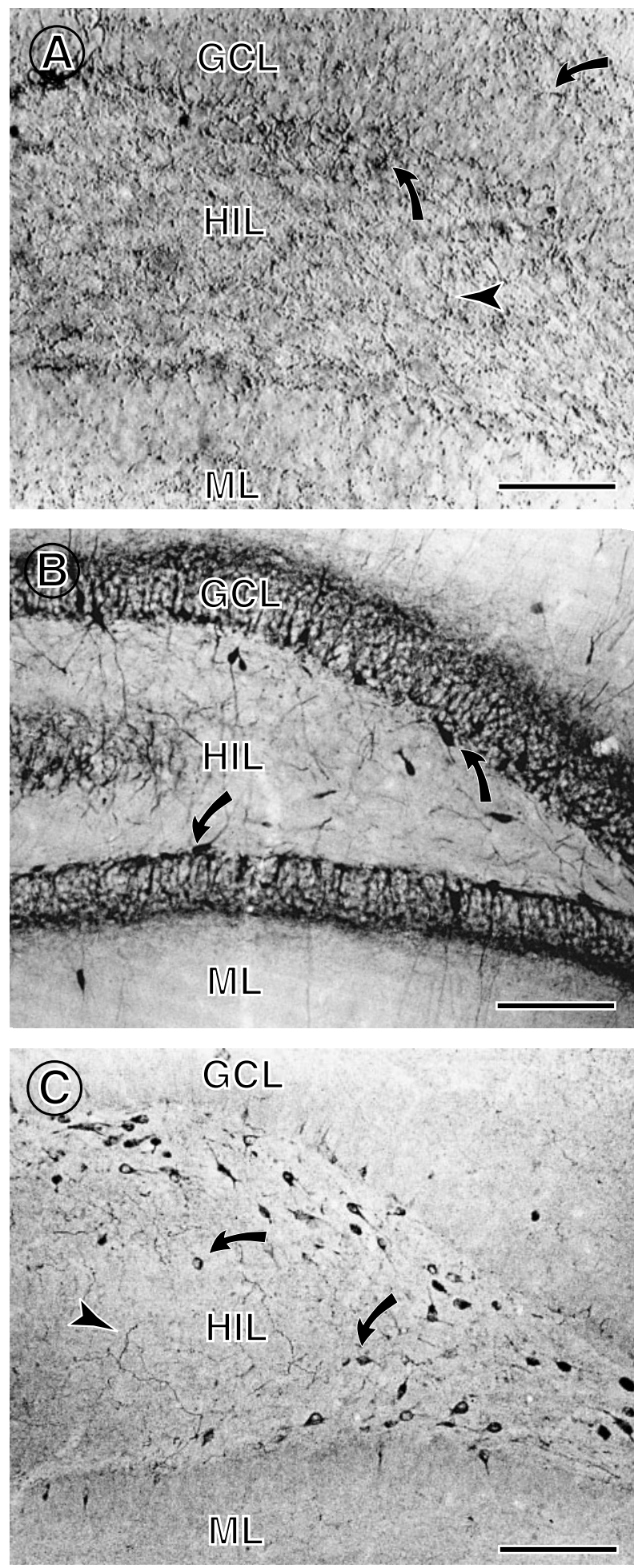

Figure 1. $\mathrm{p} 75^{\mathrm{NTR}}-\mathrm{IR}$ processes have an overlapping distribution with both PARV- and NPY-containing neuronal profiles in the dentate gyrus. $A$, p75 ${ }^{\mathrm{NTR}}$-labeled puncta and fine varicose fibers are densest in supragranular and infragranular cell layer $(G C L)$ (arrows) and more diffuse in the central portions of the hilus (HIL) (arrowhead) and molecular layer $(M L) . B$, Most PARV-IR somata and dendrites are in the infragranular region of the hilus (arrows), whereas PARV-IR fibers and puncta are dense in the granule cell layer. Scattered processes and somata with PARV immunoreactivity are seen within the molecular layer and central hilus. $C$, Numerous NPY-IR perikarya and dendrites are located within the central regions of the hilus (arrows). NPY-IR fibers are also visible in the hilus (arrowhead) Scale bars: $A-C, 400 \mu \mathrm{m}$. 


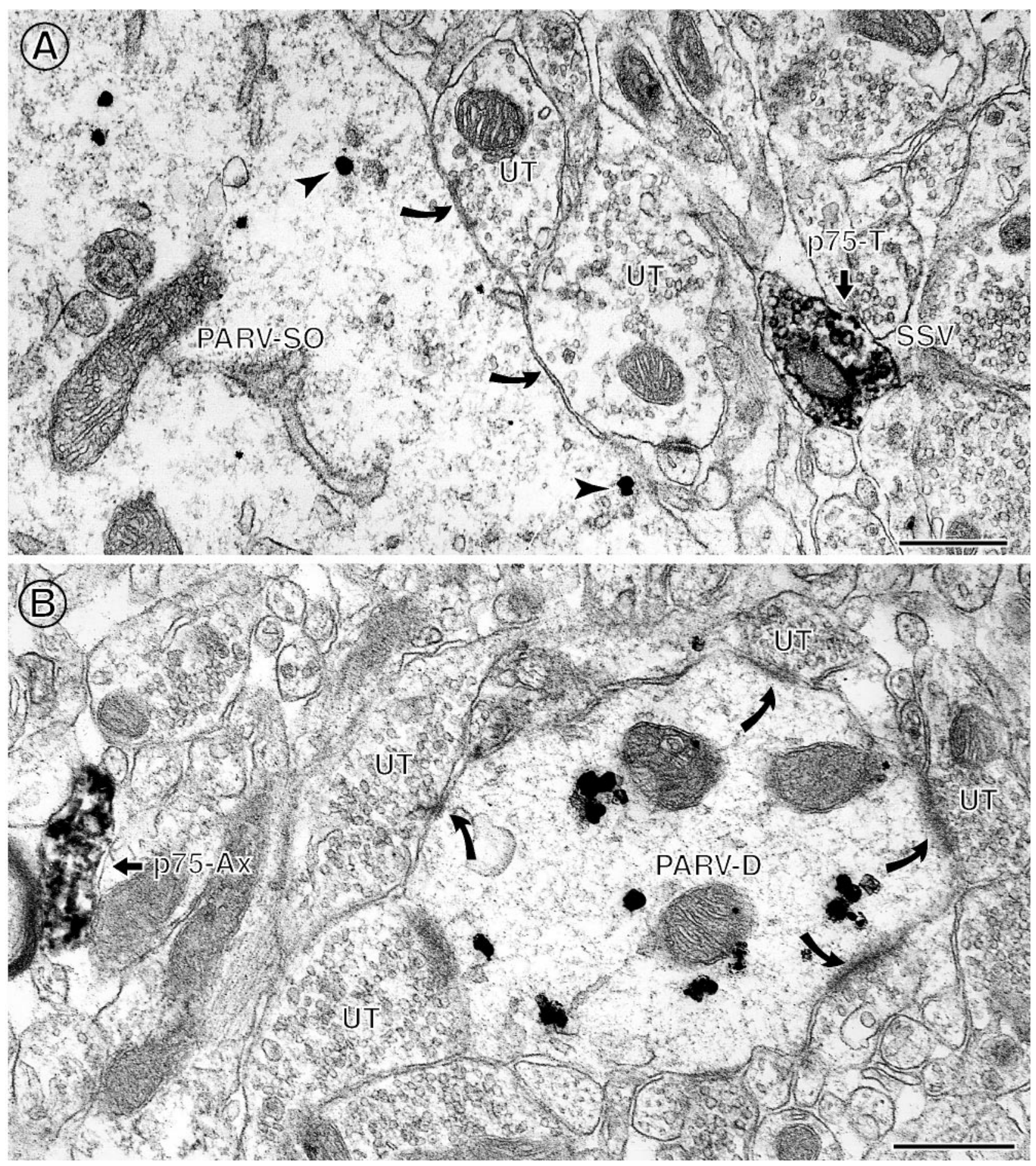

Figure 2. The majority of $\mathrm{p} 75^{\mathrm{NTR}}$-IR axons and axon terminals do not contact PARV-labeled perikarya and dendrites. $A$, In the infragranular layer, a p75 ${ }^{\text {NTR }}$-IR axon terminal $(p 75-T)$ is near but does not contact a PARV-IR soma (PARV-SO), which contains many gold-silver particles (arrowheads) within its cytoplasm. Numerous unlabeled axon terminals $(U T)$ synapse on the PARV-labeled soma (arrows). B, A p75 ${ }^{\mathrm{NTR}}$-IR axon ( $p 75$ - $\left.A x\right)$ is in the vicinity of a PARV immunogold-silver-labeled dendrite $(P A R V-D)$ in the hilus. Many unlabeled axon terminals $(U T)$ form asymmetric synapses (curved arrows) with this dendrite. $S S V$, Small synaptic vesicles. Scale bars: $A, B, 0.5 \mu \mathrm{m}$.

synapses with granule cell bodies, dendrites, and axon initial segments (data not shown).

In agreement with the pattern of PARV-IR observed at the light microscopic level, the types of PARV-IR profiles observed $(n=581)$ varied significantly between the lamina. Most PARVlabeled somal profiles $(n=43)$ occurred within the infragranular hilus and the central hilus (58 and $18 \%$, respectively). PARVlabeled dendritic profiles $(n=382)$ also occurred more frequently in the infragranular and central hilus (34\% each) than in the granule cell layer and inner molecular layer, whereas PARVlabeled axon terminal profiles $(n=156)$ were found primarily in the granule cell layer (59\%). 

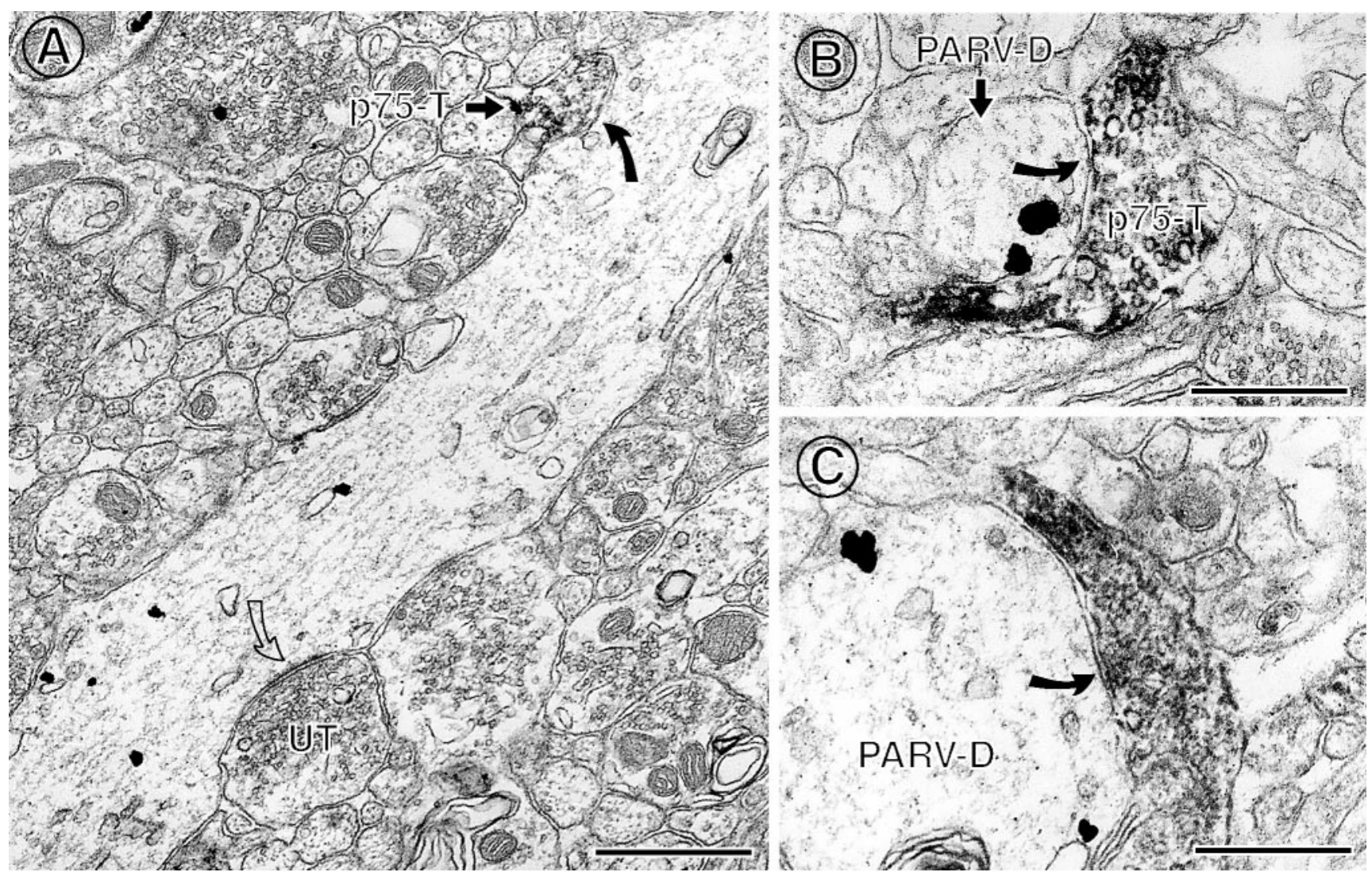

Figure 3. Occasionally, p75 ${ }^{\text {NTR }}$-IR axon terminals contact PARV-labeled dendrites. $A$, In the infragranular hilus, a p75 ${ }^{\text {NTR }}$-IR axon terminal ( $p 75-T$ ) forms a symmetric synapse (curved arrow) with a large PARV-IR dendrite (PARV-D). An unlabeled axon terminal (UT) forms a symmetric synapse (curved open arrow) with the same dendrite. $B$, In the infragranular hilus, a large p75 ${ }^{\mathrm{NTR}}$-IR axon terminal $(p 75-T)$ contacts (curved arrow) a small, PARV-IR dendrite $(P A R V-D)$. $C$, In the infragranular hilus, a large $\mathrm{p} 75^{\mathrm{NTR}}$-IR axon terminal $(p 75-T)$ forms a symmetric synapse $(c u r v e d$ arrow) with a large PARV-IR dendrite $(P A R V-D)$. Scale bars: $A, 0.65 \mu \mathrm{m} ; B, C, 0.5 \mu \mathrm{m}$.

\section{NPY immunoreactivity is in morphologically distinct subtypes of interneurons}

NPY-IR neuronal profiles in the current experiment were similar to those described in previous investigations using immunoperoxidase labeling (Deller and Leranth, 1990; Milner and Veznedaroglu, 1992, 1993; Milner et al., 1997, 1999). NPY-labeled somal profiles were either elongated or round and ranged from small $(6-12 \mu \mathrm{m}$ diameter) to medium $(12-18 \mu \mathrm{m}$ in diameter) (Figs. 5, 6; see Fig. 8). NPY-labeled somata contained immunogold-silver particles that were commonly observed near rough endoplasmic reticulum or within Golgi complex saccules and multivesicular bodies (Fig. 5A,B). At least two morphologically distinct types of NPY-labeled somata were observed: (1) those contacted by few axons and axon terminals and covered by numerous glial processes (Fig. 5) and (2) those contacted by several axons and axon terminals with very little glial coverage of their plasmalemmal surface (Fig. 6). NPY-IR dendritic profiles ranged from $1.5-5 \mu \mathrm{m}$ in diameter and primarily contained mitochondria, smooth endoplasmic reticulum, and microtubules (Figs. 7, $8 B$ ). NPY-IR perikarya and dendrites often were contacted by many axon terminals (Fig. 7). NPY-labeled axon terminals were predominantly small ( $<0.8 \mu \mathrm{m}$ in diameter) and contained many small synaptic vesicles and few mitochondria (data not shown).

Quantitative analysis of the DG revealed that the majority of NPY-IR profiles observed $(n=433)$ were located in the infragranular hilus $(n=135)$ and central hilus $(n=148)$. The majority of NPY-labeled profiles in these regions comprised somata $(n=$
$45)$ and dendrites $(n=178)$. Few NPY-containing terminals were seen $(n=58)$. Numerous NPY-labeled terminals were found in the outer molecular layer; however this region was not included in the quantitative analysis because few $\mathrm{p} 75^{\mathrm{NTR}}$-IR profiles are found here (Dougherty and Milner, 1999). Significantly fewer NPY-IR labeled profiles were found in the inner molecular layer and granule cell layer ( $n=94$ and 56, respectively).

\section{$p 75^{N T R}$-IR axon terminal associations with NPY-IR and PARV-IR profiles}

The relative frequency of immunogold-silver-labeled profiles observed in tissue labeled for PARV or NPY was not significantly different (PARV, 116 profiles per section; NPY, 108 profiles per section). Despite nearly equal densities of immunogold-silver labeling in each of these conditions, a significantly greater proportion of NPY-IR profiles received contacts from $\mathrm{p} 75^{\mathrm{NTR}}$-IR axon terminal profiles than did PARV-IR profiles $\left(\chi^{2}=8.25\right.$; $\mathrm{df}=3 ; p<0.03)$. Of all NPY-IR profiles observed, $12 \%(n=51)$ were contacted by one or more p75 ${ }^{\mathrm{NTR}}$-IR axon terminal profiles. In contrast, only $2 \%(n=12)$ of all PARV-IR profiles observed received such contacts.

Instances in which $\mathrm{p} 75^{\mathrm{NTR}}$-IR axon terminals synapsed with NPY-IR perikarya and dendrites $(n=51)$ occurred primarily in the infragranular and central hilar regions $(n=21$ and 23, respectively). These synapses were predominantly symmetric $(86 \%)$, but some were asymmetric $(14 \%)$. p $75^{\mathrm{NTR}}$-IR terminals synapsed more frequently with NPY-IR somata (57\%) than with 


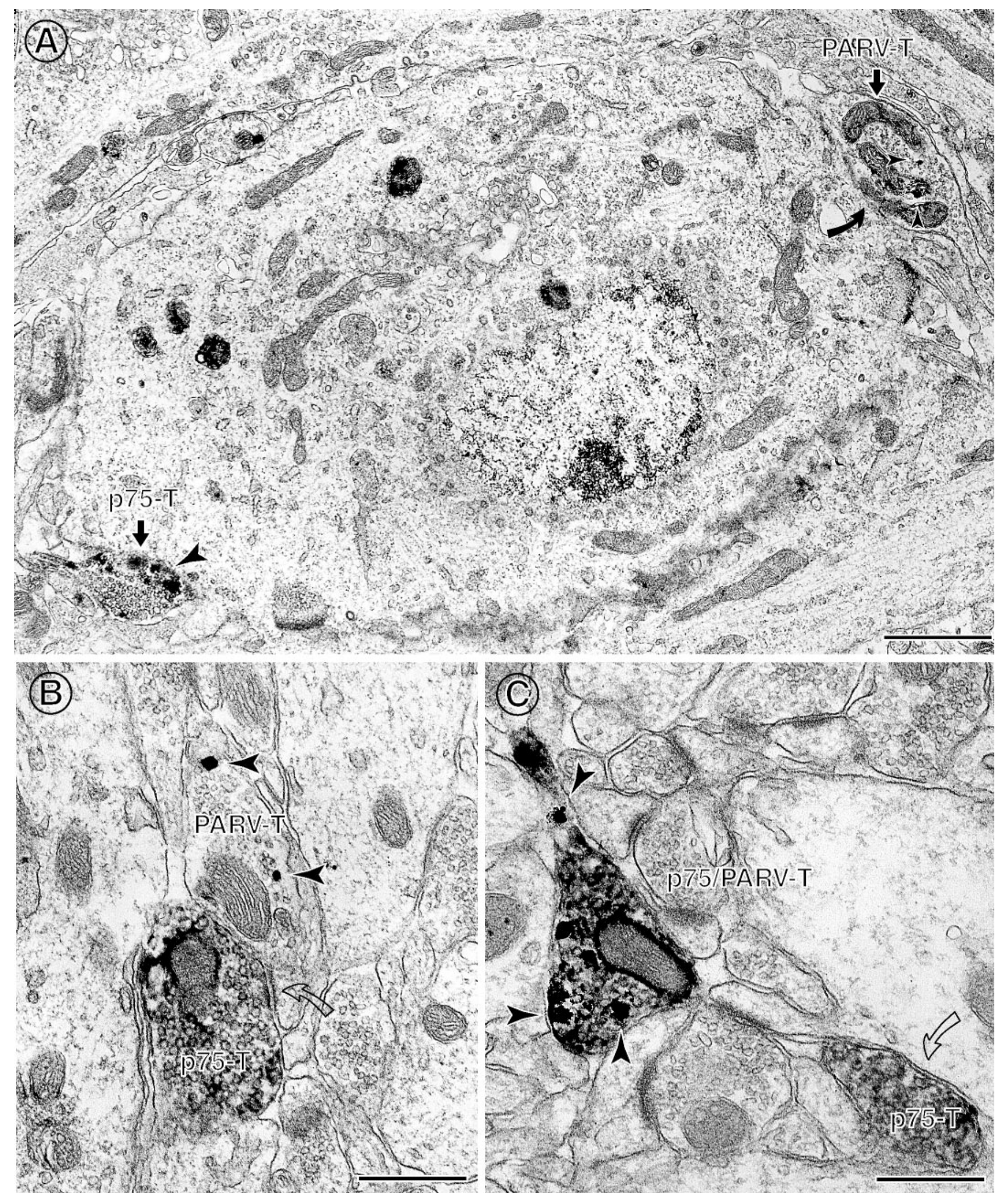

Figure 4. Rarely, p75 ${ }^{\mathrm{NTR}}$-labeled terminals are associated with PARV-containing terminals. $A$, A somata in the granule cell layer is contacted (curved arrow and arrowhead, respectively) by both a PARV-IR axon terminal (PARV-T) and a p $75^{\mathrm{NTR}}$-IR axon terminal ( $\left.p 75-T\right)$. B, In the supragranular portions of the molecular layer, a p75 ${ }^{\mathrm{NTR}}$-IR axon terminal $(p 75-T)$ abuts (curved arrow) a PARV-IR axon terminal $(P A R V$ - $T)$ labeled with gold-silver particles (arrowheads). C, An axon terminal in the supragranular layer contains both p75 ${ }^{\mathrm{N} T R}$-IR and PARV-IR gold-silver particles (arrowheads). A single-labeled, p75 ${ }^{\text {NTR }}$-IR axon terminal ( $\left.p 75-T\right)$ nearby forms a symmetric synapse (curved arrow) with an unlabeled dendrite. Scale bars: $A, 1.0 \mu \mathrm{m} ; B, C, 0.5 \mu \mathrm{m}$. 


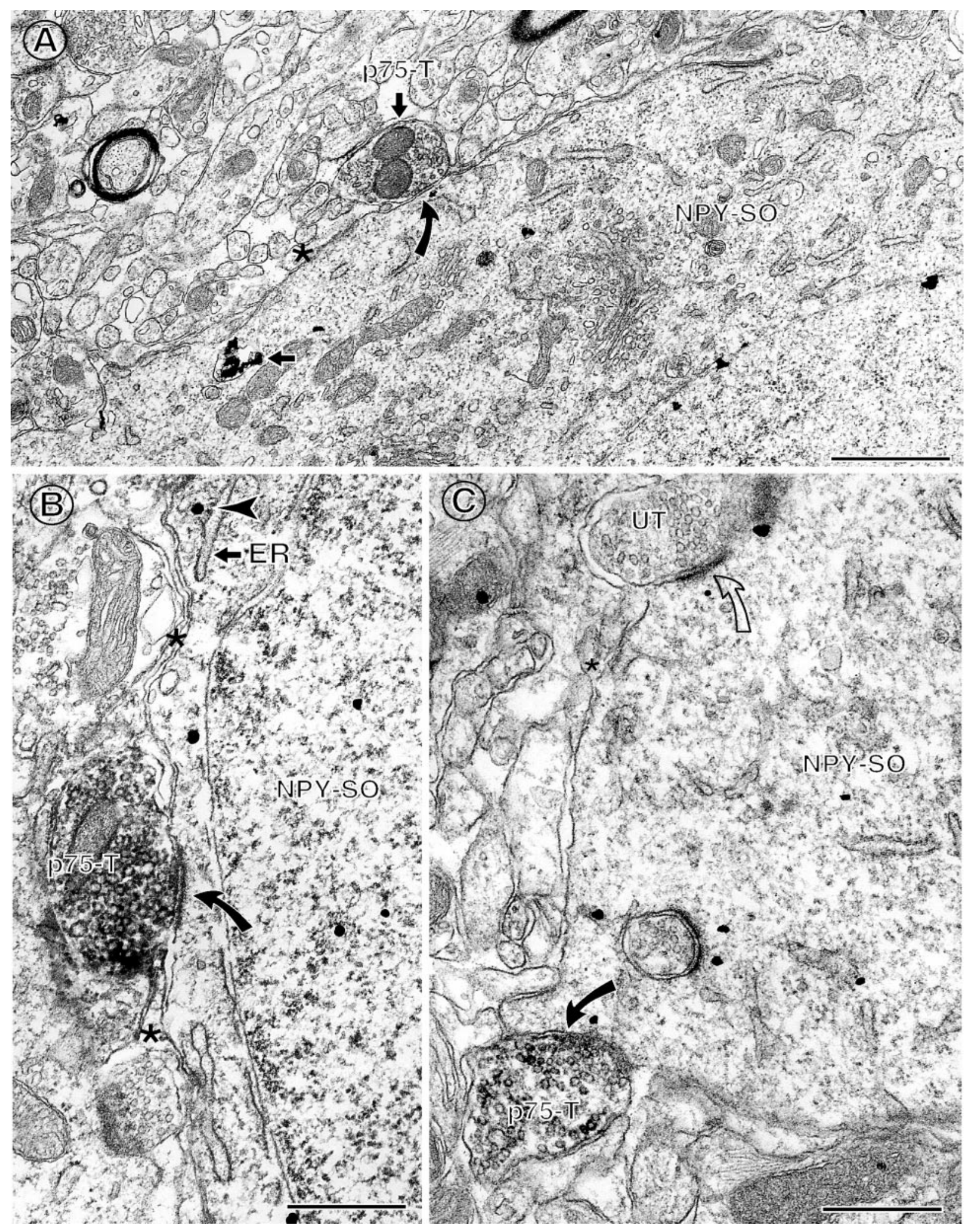

Figure 5. p75 ${ }^{\text {NTR }}$-labeled terminals commonly contact NPY-labeled perikarya with sparse inputs. $A$, In the hilus, a p75 ${ }^{\text {NTR }}$-IR axon terminal ( $p 75-T$ ) forms a symmetric synapse (curved arrow) with an NPY-IR soma (NPY-SO). This soma is contacted by few axon terminals, and its plasmalemmal surface is covered by glial profiles (asterisk). B, In the infragranular hilus, a p $75^{\mathrm{NTR}}$-IR axon terminal $(p 75-T)$ forms an asymmetric synapse (curved arrow) with an NPY-IR soma (NPY-SO) that contains gold-silver particles (arrowheads). Glial processes (asterisk) are apposed to adjacent regions of the plasmalemma. $C$, In the central hilus, much of the plasmalemmal surface of an NPY-IR soma is apposed by glial processes (asterisk). A p75 ${ }^{\mathrm{NTR}}$-IR axon terminal forms a symmetric synapse (curved arrow) with this perikaryon, whereas a nearby unlabeled axon terminal (UT) forms an asymmetric synapse (open curved arrow). Mvb, Multivesicular body; ER, endoplasmic reticulum. Scale bars: $A, B, 0.5 \mu \mathrm{m} ; C, 0.65 \mu \mathrm{m}$. 


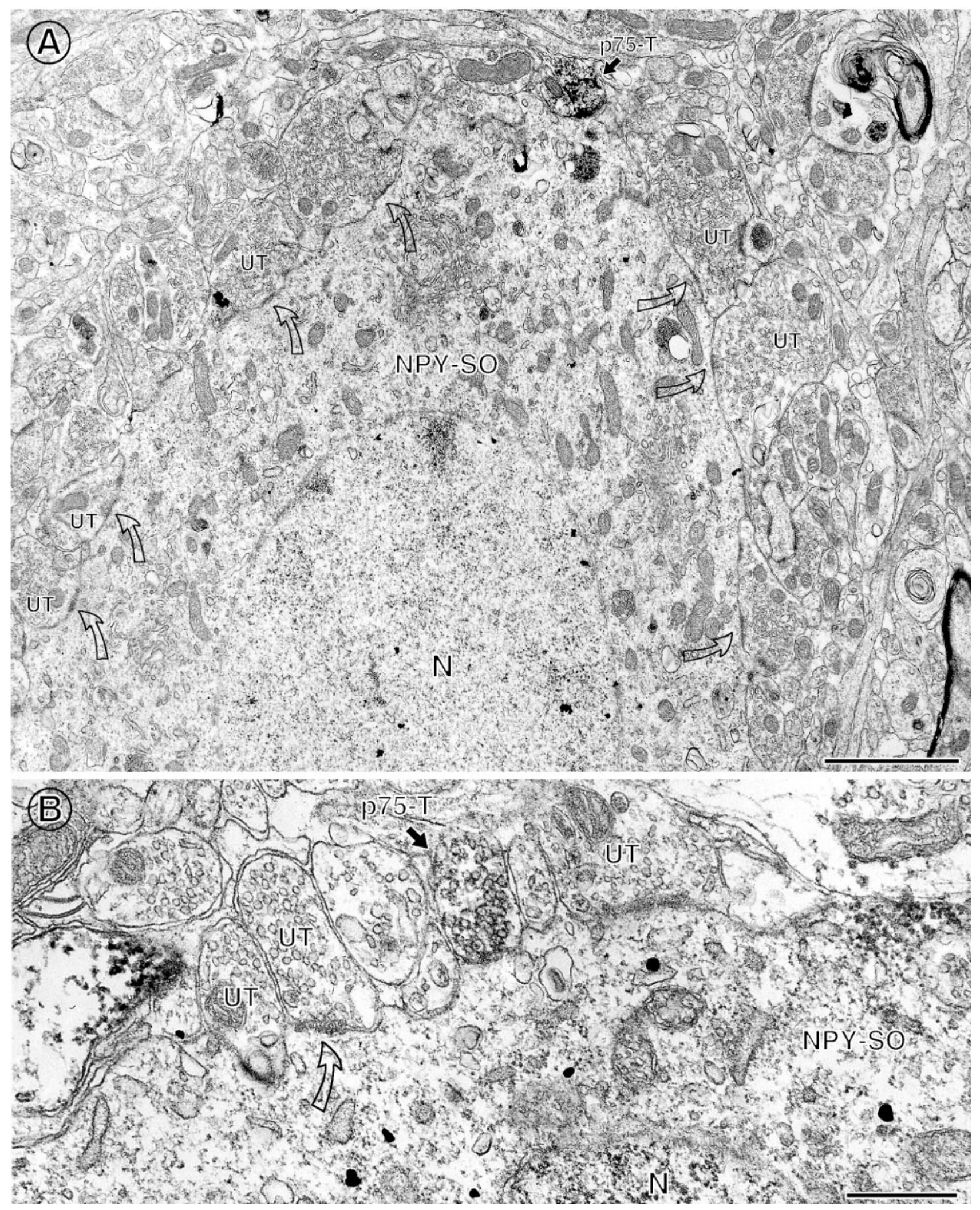

Figure 6. NPY-labeled perikarya with heavy inputs also commonly receive contacts from $\mathrm{p}^{\mathrm{N}} \mathrm{N}^{\mathrm{N}}$-labeled terminals. $A$, In the infragranular hilus, a p $75^{\text {NTR }}$-IR axon terminal ( $p 75-T$ ) establishes an asymmetric synapse (curved arrow) with an NPY-IR soma (NPY-SO). Many unlabeled axon terminals (UT) also synapse on this perikaryon (open curved arrows). B, Higher magnification view of a portion of an NPY-labeled perikaryon contacted by a p75 ${ }^{\text {NTR }}$-IR axon terminal ( $\left.p 75-T\right)$ and numerous unlabeled terminals $(U T)$ (solid curved arrows and open curved arrows, respectively). Scale bars: $A$, 1.0 $\mu \mathrm{m} ; B, 0.5 \mu \mathrm{m}$. 

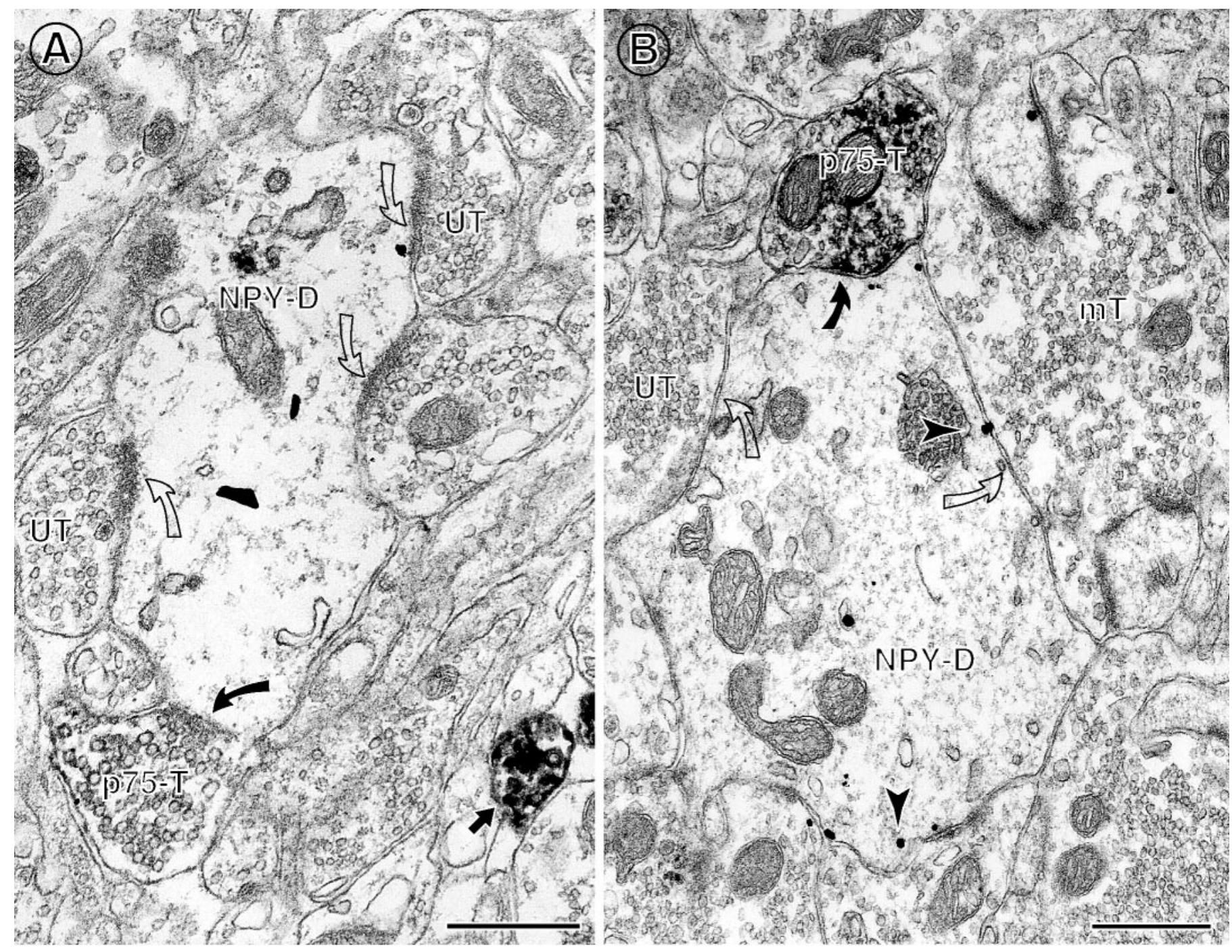

Figure 7. $\quad$ p75 NTR - IR axon terminals commonly contact NPY-IR dendrites. $A$, A p $75^{\mathrm{NTR}}$-IR axon terminal $(p 75-T)$ contacts $($ curved arrow) a large NPY-IR dendrite $(N P Y-D)$ in the hilus. Several unlabeled terminals $(U T)$ also contact (open curved arrows) this dendrite. B, A large NPY-IR dendrite $(N P Y-D)$ in the infragranular hilus is contacted by a p $75^{\text {NTR }}$-IR axon terminal ( $\left.p 75-T\right)$ that forms a symmetric synapse (curved arrow). The NPY-labeled dendrite contains many gold-silver particles located at the plasmalemma (arrowheads) and is also contacted (open curved arrows) by an unlabeled terminal $(U T)$ and an unlabeled mossy fiber terminal $(m T)$. Scale bars: $A, 1.0 \mu \mathrm{m} ; B, 0.5 \mu \mathrm{m}$.

NPY-IR dendrites (43\%) (Table 1, Figs. 5A,B, 6-8). Some NPY-IR somata $(n=3)$ and dendrites $(n=2)$ were contacted by more than one p75 ${ }^{\text {NTR }}$-IR axon terminal (Fig. $5 B$ ), which was never seen for PARV-IR profiles. Moreover, NPY-IR somata that received contacts from $\mathrm{p} 75^{\mathrm{NTR}}$-IR axon terminals fell into both morphological subtypes (i.e., those having have either very little or abundant axon terminal coverage on the plasmalemmal surface) (Figs. 5A, $B, 6,7$ ).

Target type tended to be dependent on peptide label. For instance, associations between $\mathrm{p} 75^{\mathrm{NTR}}$-IR and PARV-IR profiles tended to be axodendritic rather than axosomatic. For associations between $\mathrm{p} 75^{\mathrm{NTR}}$-IR and NPY-IR profiles, the reverse was true: the majority of synapses formed were axosomatic and fewer were axodendritic (Table 1). Moreover, synaptic associations between p75 ${ }^{\text {NTR }}$-IR terminals and PARV-IR perikarya and dendrites were exclusively symmetric, whereas synaptic associations between p75 ${ }^{\text {NTR }}$-IR terminals and NPY-IR perikarya and dendrites were predominantly symmetric, but also asymmetric (Table 1).

Unlike NPY-labeled profiles, which were almost exclusively perikarya and dendrites in the regions analyzed, a number of PARV-IR profiles were axon terminals. Rarely, $(n=1)$ a p75 ${ }^{\text {NTR }}$-IR axon terminal and a PARV-IR axon terminal contacted the same perikaryon (Fig. 4A). Equally rare was the identification of axoaxonic contacts between a p75 ${ }^{\mathrm{NTR}}$-IR axon terminal and a PARV-IR axon terminal (Fig. 4B). Moreover, a few axon terminal profiles $(n=4)$ contained immunoreaction product for both p75 ${ }^{\text {NTR }}$ - and PARV-IR (Fig. $4 C$ ).

\section{DISCUSSION}

These results suggest that septal cholinergic afferents to the dentate gyrus: (1) preferentially innervate NPY-containing interneurons compared to those labeled with PARV and (2) may provide a more powerful (i.e., somatic innervation), yet functionally diverse (i.e., asymmetric and symmetric synapses) modulation of NPY-containing interneurons. Moreover, they provide evidence that neurochemical subsets of hippocampal interneurons can be distinguished by afferent input. 

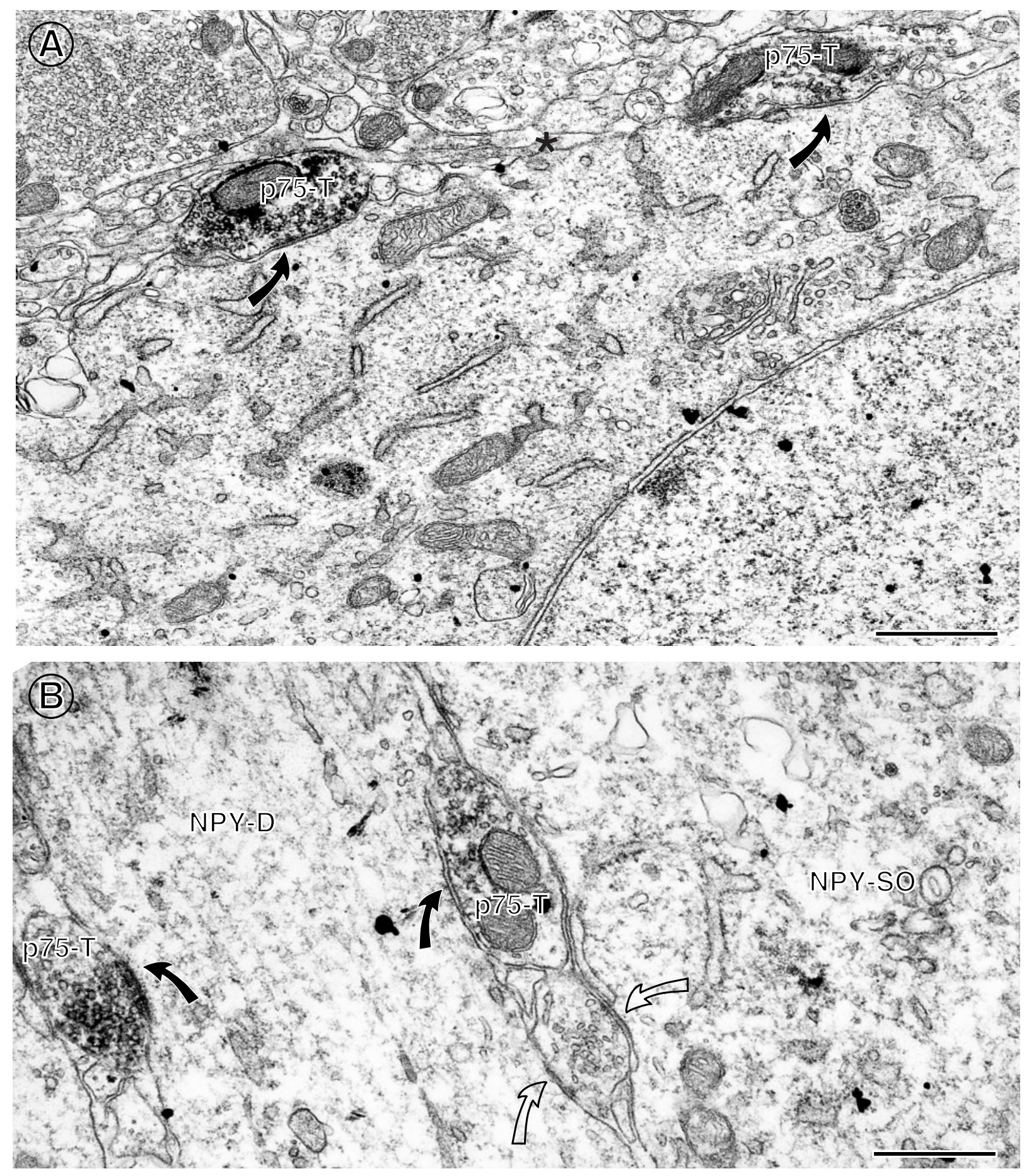

Figure 8. Often, more than one p75 ${ }^{\mathrm{NTR}}$-IR terminal contacts an NPY-labeled perikaryon or dendrite. $A$, Two p $75^{\mathrm{NTR}}$-labeled terminals $(p 75-T)$ form symmetric synapses (curved arrows) with the same NPY-containing soma (NPY-SO). This soma received few contacts from other terminals. $B$, . A large NPY-labeled dendrite is contacted (curved arrows) by two p $75^{\mathrm{NTR}}$-IR terminals ( $\left.p 75-T\right)$. An unlabeled terminal (UT) also contacts (open arrow) the same dendrite as well as a neighboring NPY-IR soma. Scale bars, $0.5 \mu \mathrm{m}$.

\section{Cholinergic septal afferent terminals form more contacts with NPY-IR neurons than PARV-IR neurons}

In the present investigation, p $75^{\mathrm{NTR}}$-IR axon terminals, presumably arising from cholinergic neurons in the septal complex (Dougherty and Milner, 1999), contacted a significantly greater proportion of NPY-IR profiles than PARV-IR profiles. Moreover, some NPY-IR targets were contacted by two or more p75 NTR -IR axon terminals. According to their location and morphology, the majority of NPY-IR cells likely correspond to hilar perforant path-associated (HIPP) cells (Han et al., 1993; Halasy and Somogyi, 1993; Freund and Buzsáki, 1996; Sik et al., 1997). The axon terminals of these cells, many of which also contain somatostatin, contact the dendrites of granule cells, overlapping with the termination zones of glutamatergic entorhinal afferent 


\begin{tabular}{|c|c|c|c|c|c|}
\hline \multicolumn{6}{|c|}{$\begin{array}{l}\text { Table 1. Relation of } \mathrm{p} 5^{\mathrm{NTR}} \text {-IR axon terminals to PARV- and NPY-IR } \\
\text { profiles }\end{array}$} \\
\hline & \multirow{2}{*}{$\begin{array}{l}\text { Total number } \\
\text { of contacted } \\
\text { profiles }\end{array}$} & \multicolumn{2}{|c|}{$\begin{array}{l}\mathrm{p} 75^{\mathrm{NTR}} \text {-IR termi- } \\
\text { nals contacting }\end{array}$} & \multicolumn{2}{|c|}{$\begin{array}{l}\text { Synapse type formed by } \\
\text { p } 75^{\text {NTR }} \text {-IR terminals }\end{array}$} \\
\hline & & Somata & Dendrites & Asymmetric & Symmetric \\
\hline PARV & 14 & 2 & 12 & 0 & 12 \\
\hline NPY & 51 & 33 & $25^{*}$ & 14 & 44 \\
\hline
\end{tabular}

Total number of profiles observed: PARV, 581; NPY, 433.

*For NPY/p75 ${ }^{\mathrm{NTR}}$ contacts, the number of contacts formed by $\mathrm{p} 75^{\mathrm{NTR}}$-IR terminal profiles exceeds total number of NPY-IR profiles because of the occurrence of multiple contacts on a single NPY-IR profile.

fibers (Deller and Leranth, 1990). These cells therefore are ideally situated to provide spatial control of the ability of granule cell dendrites to support backpropagation and may be instrumental regulators of synaptic plasticity by modulating excitatory inputs to granule cells (Klapstein and Colmers, 1997; Paulsen and Moser, 1998). Conversely, PARV-IR neurons correspond to perisomatic inhibitory interneurons or basket cells, which contact granule cells and mediate both feedback and feedforward inhibition (Ribak et al., 1990; Han et al., 1993; Halasy and Somogyi, 1993; Fukuda et al., 1996).

Several different, but not mutually exclusive, mechanisms may account for selective targeting of NPY-IR structures by cholinergic axon terminals. For example, cholinergic neurons in the adult rat septal complex are critically dependent on neurotrophins derived from target structures for their survival. Recent reports suggest that subpopulations of hippocampal interneurons produce unique combinations of neurotrophins (Pascual et al., 1999). Some cholinergic axons may possibly target those structures that produce the necessary neurotrophic combination. The large majority of both PARV-IR basket cells and NPY-IR interneurons in the dentate gyrus contain nerve growth factor (NGF) mRNA and thus likely produce NGF; however, neurotrophin-3 (NT-3) is found within most NPY-IR interneurons in the dentate gyrus, but only a small subset of PARV-IR interneurons (Pascual et al., 1999). The possibility that adult septal cholinergic axons in the dentate gyrus are attracted toward and preferentially synapse with cells that produce both NGF and NT-3 may underlie the current findings. Moreover, hippocampal interneurons may also depend on neurotrophic support for survival (Ha et al., 1998), and recent reports (Cho et al., 1998; Milner et al., 1999) suggest that they may derive a portion of this (especially NGF) from their septal cholinergic associations.

\section{Cholinergic septal afferents preferentially contact NPY-IR somata}

Most associations between septal cholinergic afferents and NPY-IR neurons were axosomatic. In contrast, the majority of contacts between $\mathrm{p} 75^{\mathrm{NTR}}$ and PARV profiles were axodendritic. Perikaryal contacts may exert a more rapid and potent effect on the cell than do dendritic inputs (Spruston et al., 1994; Milner et al., 1999). Moreover, somatic synapses regulate action potential firing whereas dendritic synapses influence efficacy of specific types of afferent innervation (Paulsen and Moser, 1998). This differential pattern of connectivity, combined with the greater overall innervation of NPY-IR profiles compared to PARV-IR profiles, suggests that activation of septohippocampal cholinergic fibers is heavily weighted toward influencing NPY-IR rather than PARV-IR interneurons.

p $75^{\text {NTR }}$-IR axon terminals formed synapses with both classes of NPY-IR somata: (1) those with sparse associations from axons and axon terminals and a high degree of plasmalemmal astrocytic coverage and (2) those with dense associations from many axons and axon terminals and concomitantly less astrocytic coverage. These observations add to the growing body of evidence that functional and/or morphologically distinct subgroups of interneurons exist in the hippocampal formation (Freund and Buzsáki, 1996; McQuiston and Madison, 1999; Pascual et al., 1999; Svoboda et al., 1999). Our recent study (Milner et al., 1999) indicates that a subset of cholinergically targeted NPY interneurons located in the central hilus may depend on such input for survival. Further investigations are needed to examine whether degree of terminal coverage compared to astrocytic coverage of the plasmalemma determines vulnerability of NPY interneurons after loss of cholinergic input. Moreover, the morphological variations between NPY-IR perikarya we observed in the current investigation (i.e., many overall terminal contacts vs few terminal contacts) may be relevant to determining the functional consequences of cholinergic activation among these somata; those cells having few contacts may be more potently modulated by cholinergic inputs than those cells having many terminal contacts.

\section{The type of synapse formed by cholinergic septal afferents varies depending on the target}

We found that the type of synapses formed by cholinergic hippocampal afferents is, at least in part, dependent on target type. In agreement with previous work (Dougherty and Milner, 1999), p75 ${ }^{\text {NTR }}$-IR axon terminals formed both symmetric and asymmetric synaptic associations with their NPY-IR targets. However, when contacting PARV-IR targets, such axon terminals formed exclusively symmetric synapses. Under these circumstances, postsynaptic responses may heavily depend on the presence of various classes of cholinergic receptors, the neurochemical content of other afferents a given target receives, and/or the degree to which these inputs are active. Physiological studies have shown that diverse responses to cholinergic excitation may be mediated by the activation of various classes of muscarinic and nicotinic cholinergic receptors on functionally distinct subsets of hippocampal interneurons (Behrends and Bruggencate, 1993; McQuiston and Madison, 1999). Moreover, anatomical studies indicate that cholinergic receptors are not only differentially distributed within the cellular compartments of subsets hippocampal interneurons, but that they are differentially regulated by cholinergic septal input (Levey et al., 1995; Hájos et al., 1998). Together, these findings suggest that acetylcholine release may lead to either inhibition or excitation within the same cell, as well as among possibly distinct interneuron populations.

\section{Cholinergic septal afferents have additional relationships with PARV-IR neurons}

Occasional instances of other types of interactions between p75 ${ }^{\text {NTR }}$-IR axon terminals and PARV-IR neuronal profiles were observed in this study. In a few instances, p75 NTR-IR axon terminals and PARV-IR axon terminals were in close proximity or directly apposed, raising the possibility that PARV-IR axon terminals may modulate septal cholinergic hippocampal afferents or vice versa. Some granule cell profiles were contacted by both a p75 ${ }^{\text {NTR }}$-IR axon terminal and a PARV-IR axon terminal, likely to originate from a basket cell in the infragranular region of the hilus (Ribak et al., 1990). This observation suggests that PARVcontaining basket cells and septal cholinergic afferents could modulate the same populations of principal cells. In rare in- 
stances, PARV-IR and p75 ${ }^{\text {NTR }}$-IR were colocalized in the same neuronal profile, indicating that some PARV-IR hippocampal neurons and/or septal PARV-IR afferents are responsive to one or more of the neurotrophins. The recent finding that many PARV-IR hilar interneurons produce NGF (Pascual et al., 1999), together with our observation of the $\mathrm{p} 75^{\mathrm{NTR}}$ within these cells, provides further evidence suggesting that in the adult, neurotrophin production may be regulated in an autocrine fashion, with local neurotrophin concentrations possibly acting as a component of a negative feedback loop (Zaremba and Dreyfus, 1999).

\section{Functional significance}

Investigations of both humans and animals have implied indirectly the existence of an association between cholinergic septal afferents and NPY-containing interneurons. In humans with epilepsy and dementia and among experimental animals after seizure induction, both septal cholinergic cells and/or hippocampal NPY/SOM-containing interneurons degenerate (Chan-Palay et al., 1986; Babb et al., 1989; Lehéricy et al., 1991; Freund et al., 1992; Sloviter, 1994). As presumptive modulators of hippocampal interneurons, any alteration in septohippocampal afferents may affect the cellular mechanisms that underlie learning and memory. Hippocampal interneurons have been proposed to provide the spatial and temporal conditions necessary for synaptic modifications that may underlie hippocampal-dependent memory encoding and retrieval (Paulsen and Moser, 1998). The current findings, together with previous evidence (Milner et al., 1997; Freund and Antal, 1988), suggest that septal afferents form synaptic associations with hippocampal interneurons in a transmitter-specific fashion, such that GABAergic septal afferents predominantly contact GABAergic basket cells and cholinergic septal afferents preferentially target NPY-IR HIPP interneurons. Consequently, GABAergic and cholinergic septal afferents may modulate inputs to hippocampal granule cells via separate interneuron populations. Each of these populations may be involved in synaptic plasticity: NPY-IR HIPP cells are ideally situated to provide control of dendritic segments to support backpropagation, whereas basket and chandelier cells, which contact principal cell somata and axon initial segments, synchronize principal cell activity and mediate feedback inhibition (for review, see Paulsen and Moser, 1998). Basket and chandelier cells may also achieve temporal control of dendritic action potentials by phasing action potential generation in the soma (Parra et al., 1998). Death of basal forebrain cholinergic neurons, such as that seen in Alzheimer's disease, therefore is likely to lead to a loss of cholinergic modulation of HIPP cells, whereas GABAergic input onto basket cells remains intact. Functionally, this may lead to profound granule cell inhibition, as well as a desynchronization of granule cell responsiveness.

\section{REFERENCES}

Amaral DG, Kurz J (1985) An analysis of the origins of the cholinergic and non-cholinergic septal projections to the hippocampal formation of the rat. J Comp Neurol 240:37-59.

Babb TL, Pretorius JK, Kupfer WR, Crandall PH (1989) Glutamate decarboxylase-immunoreactive neurons are preserved in human epileptic hippocampus. J Neurosci 9:2562-2574.

Baxter MG, Holland PC, Gallagher M (1997) Disruption of decrements in conditioned stimulus processing by selective removal of hippocampal cholinergic input. J Neurosci 17:5230-5236.

Behrends, JC, Bruggencate G (1993) Cholinergic modulation of synaptic inhibition in the guinea pig hippocampus in vitro: excitation of GABAergic interneurons and inhibition of GABA release. J Neurophysiol 69:626-629.

Chan J, Aoki C, Pickel VM (1990) Optimization of differential immunogold-silver and peroxidase labeling with maintenance of ultrastructure in brain sections before plastic embedding. J Neurosci Methods 33:113-127.

Chan-Palay V, Lang W, Haesler U, Köhler C, Yasagril G (1986) Distribution of altered hippocampal neurons and axons immunoreactive with antisera against neuropeptide Y in Alzheimer's-type dementia. J Comp Neurol 248:376-394.

Chandler CE, Parsons LM, Hosang M, Shooter EM (1984) A monoclonal antibody modulates the interaction of nerve growth factor with PC12 cells. J Biol Chem 259:6882-6889.

Chiba AA, Bucci DJ, Holland PC, Gallagher M (1995) Basal forebrain cholinergic lesions disrupt increments but not decrements in conditioned stimulus processing. J Neurosci 15:7315-7322.

Cho HJ, Kim JK, Park HC, Kim DS, Ha SO, Hong HS (1998) Changes in brain-derived neurotrophic factor immunoreactivity in rat dorsal root ganglia, spinal cord, and gracile nuclei following cut or crush injuries. Exp Neurol 154:224-230.

Clarke DJ (1985) Cholinergic innervation of the rat dentate gyrus: An immunocytochemical and electron microscopical study. Brain Res 360:349-354.

Deller T, Leranth C (1990) Synaptic connections of neuropeptide Y (NPY) immunoreactive neurons in the hilar area of the rat hippocampus. J Comp Neurol 300:433-447.

Deller T, Nitsch R, Frotscher M (1994) Associational and commissural afferents of parvalbumin-immunoreactive neurons in the rat hippocampus: a combined immunocytochemical and PHA-L study. J Comp Neurol 350:612-622.

Dobrowsky RT, Werner MH, Castellino AM, Chao MV, Hannun YA (1994) Activation of the sphingomyelin cycle through the low-affinity neurotrophin receptor. Science 265:1596-1599.

Dougherty KD, Milner TA (1998) p $75^{\text {NTR }}$ immunoreactive terminals differentially innervate hilar neuropeptide $\mathrm{Y}$ and parvalbumin interneurons. Soc Neurosci Abstr 24:40.

Dougherty KD, Milner TA (1999) p $75^{\text {NTR }}$-immunoreactivity in the rat dentate gyrus is mostly within presynaptic profiles but also found in some astrocytic and postsynaptic profiles. J Comp Neurol 407:77-91.

Freund TF (1989) GABAergic septohippocampal neurons contain parvalbumin. Brain Res 478:375-381.

Freund TF, Antal M (1988) GABA-containing neurons in the septum control inhibitory interneurons in the hippocampus. Nature 336:170-173.

Freund TF, Buzsáki G (1996) Interneurons of the hippocampus. Hippocampus 6:347-470.

Freund TF, Ylinen A, Meittinen R, Pitkanen A, Lahtinen H, Baimbridge KG, Riekkinen PJ (1992) Pattern of neuronal death in the rat hippocampus after status epilepticus. Relationship to calcium binding protein content and ischemic vulnerability. Brain Res Bull 28:27-38.

Frotscher M (1991) Target cell specificity of synaptic connections in the hippocampus. Hippocampus 1:123-130.

Fukuda T, Aika Y, Heizmann CW, Kosaka T (1996) Dense GABAergic input on somata of parvalbumin-immunoreactive GABAergic neurons in the hippocampus of the mouse. Neurosci Res 26:181-194.

Ha DH, Robertson RT, Weiss JH (1998) Distinctive morphological features of a subset of cortical neurons grown in the presence of basal forebrain neurons in vitro. J Neurosci 18:4201-4215.

Hájos N, Papp EC, Acsády L, Levey AI, Freund TF (1998) Distinct interneuron types express M2 muscarinic receptor immunoreactivity on their dendrites or axon terminals in the hippocampus. Neurosci 82:355-376.

Halasy K, Somogyi P (1993) Subdivisions in the multiple GABAergic innervation of granule cells in the dentate gyrus of the rat hippocampus. Eur J Neurosci 5:411-429.

Han Z-S, Buhl EH, Lorinczi Z, Somogyi P (1993) A high degree of spatial selectivity in the axonal and dendritic domains of physiologically identified local circuit neurons in the dentate gyrus of the rat hippocampus. Eur J Neurosci 5:395-410.

Klapstein GJ, Colmers WF (1997) Neuropeptide Y suppresses epileptiform activity in rat hippocampus in vitro. J Neurophysiol 78:1651-1661.

Köhler C, Chan-Palay V, Wu JY (1984) Septal neurons containing glutamic acid decarboxylase immunoreactivity project to the hippocampal region in the rat brain. Anat Embryol 169:41-44.

Koliatsos VE, Price DL, Gouras GK, Cayouette MH, Burton LE, Winslow JW (1994) Highly selective effects of nerve growth factor, brainderived neurotrophic factor, and neurotrophin-3 on intact and injured basal forebrain magnocellular neurons. J Comp Neurol 343:247-262. 
Kosaka T, Katsumara H, Hama K, Wu JY, Heizmann CW (1987) GABAergic neurons containing the $\mathrm{Ca}^{2+}$-binding protein parvalbumin in the rat hippocampus and dentate gyrus. Brain Res 419:119-130.

Lehéricy S, Hirsch EC, Hersh LB, Agid Y (1991) Cholinergic neuronal loss in the globus pallidus of Alzheimer disease patients. Neurosci Lett 123:152-155.

Levey AI, Edmunds SM, Koliatsos VE, Wiley RG, Heilman CJ (1995) Expression of $\mathrm{m} 1-\mathrm{m} 4$ muscarinic acetylcholine receptor proteins in rat hippocampus and regulation by cholinergic innervation. J Neurosci 15:4077-4092.

Magee JC, Johnston D (1997) A synaptically controlled, associative signal for Hebbian plasticity in hippocampal neurons. Science 275:209-213.

McQuiston AR, Madison DV (1999) Nicotinic receptor activation excites subtypes of interneurons in the rat hippocampus. J Neurosci 19:2887-2896.

Milner TA, Loy R, Amaral DG (1983) An anatomical study of the development of the septo-hippocampal projection in the rat. Dev Brain Res 8:343-371.

Milner TA, Wiley RG, Kurucz OS, Prince SR, Pierce JP (1997) Selective changes in hippocampal neuropeptide Y neurons following removal of the cholinergic septal inputs. J Comp Neurol 386:46-59.

Milner TA, Hammel JR, Ghorbani TT, Wiley RG, Pierce JP (1999) Septal cholinergic deafferentation of the dentate gyrus results in a loss of a subset of neuropeptide Y somata and an increase in synaptic area on remaining neuropeptide Y dendrites. Brain Res 831:322-336.

Milner TA, Veznedaroglu E (1992) Ultrastructural localization of neuropeptide Y-like immunoreactivity in the rat hippocampal formation. Hippocampus 2:107-126.

Milner TA, Veznedaroglu E (1993) Septal efferent axon terminals identified by anterograde degeneration show multiple sites for modulation of Neuropeptide Y-like containing neurons in the rat dentate gyrus. Synapse 14:101-112.

Muir JL (1997) Acetylcholine, aging and Alzheimer's disease. Pharmacol Biochem Behav 56:687-696.

Parra P, Gulyas AI, Miles R (1998) How many subtypes of inhibitory cells in the hippocampus? Neuron 20:983-993.

Pascual M, Acsády L, Rocamora N, Freund TF, Soriano E (1999) Expression of neurotrophins in hippocampal interneurons immunoreactive for the neuropeptides somatostatin, neuropeptide-Y, vasoactive intestinal polypeptide and cholecystokinin. Neuroscience 89:1089-1101.

Patton PE, McNaughton B (1995) Connection matrix of the hippocampal formation.1. The dentate gyrus. Hippocampus 5:245-286.

Paulsen O, Moser EI (1998) A model of hippocampal memory encoding and retrieval: GABAergic control of synaptic plasticity. Trends Neurosci 21:273-278.

Peters A, Palay SL, Webster HD (1991) The fine structure of the nervous system, Ed 3. New York: Oxford UP.

Pioro EP, Cuello AC (1990) Distribution of NGF receptor-like immunoreactivity in the adult rat CNS: effect of colchicine and correlation with the cholinergic system -I. Forebrain. Neuroscience 34:57-87.

Ribak CE, Nitsch R, Seress L (1990) Proportion of parvalbumin-positive basket cells in the GABAergic innervation of pyramidal and granule cells of the rat hippocampal formation. J Comp Neurol 300:449-461.

Senut M-C Menetry D, Lamour Y (1989) Cholinergic and peptidergic projections from the medial septum and the nucleus of the diagonal band of Broca to dorsal hippocampus, cingulate cortex and olfactory bulb: a combined WAHG immunohistochemical study. Neuroscience 30:385-404.

Sik A, Penttonen M, Buzsáki G (1997) Interneurons in the hippocampal dentate gyrus: an in vivo intracellular study. Eur J Neurosci 9:573-588.

Sloviter RS (1994) The functional organization of the hippocampal dentate gyrus and its relevance to the pathogenesis of temporal lobe epilepsy. Ann Neurol 35:640-654.

Sloviter RS, Nilavier G (1987) Immunocytochemical localization of GABA, CCK-, VIP-, and SOM-like immunoreactivity in the area dentata and hippocampus of the rat. J Comp Neurol 256:42-60.

Spruston N, Jaffe DB, Johnston D (1994) Dendritic attenuation of synaptic potentials and currents: the role of passive membrane properties. Trends Neurosci 17:161-166.

Svoboda KR, Adams CE, Lupica CR (1999) Opioid receptor subtype expression defines morphologically distinct classes of hippocampal interneurons. J Neurosci 19:85-95.

Swanson LW, Cowan WM (1979) The connections of the septal region in the rat. J Comp Neurol 186:621-656.

Zaremba TM, Dreyfus CF (1999) Identification and regulation of NGF, BDNF and NT3 as mediators of glial trophic activity. In: Neurotrophins. New York: Wiley. 